\title{
El cuerpo como territorio de control: expresión del deseo desde lo femenino y Io masculino**
}

\section{The body as a territory of control: expression of desire from the feminine and the masculine.}

\author{
Anamaria Martínez Ramirez ${ }^{* *}$ \\ Angie Tatiana Yate Capera ${ }^{* *}$ \\ Brayan Steven Fonseca Rey ${ }^{* * *}$ \\ Claudia Melissa Armero Moreno ${ }^{* * * *}$ \\ Dayana Alfonso Morales \\ Juan David Tovar Pinilla.
}

\section{Resumen}

La relación entre el deseo y el cuerpo como territorio de control para la constitución de las ficciones políticas de feminidad y masculinidad exige el estudio de los postulados del siglo xx y su evolución contrastada con lecturas contemporáneas. Proponemos, así, las categorías de psicoanálisis Freudiano con la patologización del deseo femenino y el poder institucional de Foucault. Serán revisadas las visiones en virtud de la irrupción del fenómeno queer, lo performativo

\footnotetext{
* $\quad$ Articulo de Revisión.

** Anamaría Martínez Ramírez. Contacto: amartinezr@academia.usbbog.edu.co

***_Angie Tatiana Yate Capera. Contacto: atyatec@academia.usbbog.edu.co

$\star * \star * \quad B r a y a n$ Steven Fonseca Rey. Contacto: bsfonsecar@academia.usbbog.edu.co

$\star * * * \star \quad C l a u d i a$ Melissa Armero Moreno. Contacto: cmarmerom@academia.usbbog.edu.co

$\star \star * \star \star *$ Dayana Alonso Morales. Contacto: dalfonsom@academia.usbbog.edu.co

$\star \star \star \star \star \star$ Juan David Tovar Pinilla. Contacto: jdtovarp1@academia.usbbog.edu.co
} 
del género en Butler, el imperio excluyente de la heterónoma a partir de la relación consecuente entre sexo-género-deseo y las lecturas sociológicas de Connell y Sara Martín en la construcción identitaria de la masculinidad viril. Por último, en el intento de vislumbrar una episteme alternativa, se propone el modelo farmocopornográfico de Preciado, que converge dos industrias: la farmacéutica, puntualizando el análisis en la píldora anticonceptiva, y la pornográfica, como instrumento semiótico para la construcción y manipulación del placer. Los dispositivos biotecnológicos abordados permitirán transitar de las lógicas socioculturales al lente de lo bioquímico, concluyendo que lo molecular también es político.

\section{Palabras clave}

Cuerpo, deseo, control, feminidad, masculinidad.

\section{Abstract}

The relationship between desire and the body as a territory of control for the construction of the political fictions of femininity and masculinity, demands the study of the postulates of the 20th century and their evolution contrasted with contemporary readings. Thus, we propose the categories of Freudian psychoanalysis with the pathologization of feminine desire and Foucault's institutional power. The views will be reviewed by virtue of the irruption of the queer phenomenon, the gender performative in Butler, the excluding empire of the heteronorma from the consequent relationship between sex-gender-desire and the sociological readings of Connell and Sara Martin in the identity construction of virile masculinity. Finally, in the attempt to glimpse an alternative episteme, Preciado's pharmacopornographic model is proposed, which converges two industries: pharmaceutical, pointing out the analysis in the birth control pill; and pornographic, as a semiotic instrument for the construction and manipulation of pleasure. Biotech devices addressed 
will allow the transition from socio-cultural logics to the lens of the biochemical by concluding that the molecular is political.

\section{Keywords}

Body, desire, control, femininity, masculinity.

\section{Introducción}

La historia del ser humano se ha visto marcada por diversos ideales que han reinado en las diferentes sociedades, entre los cuales se encuentran las ideas del poder y la fuerza como fin último para la realización del ser, y la dominación e imposición como el medio oportuno y adecuado para la reivindicación de esa coacción. Pues bien, en virtud del sinfín de posibilidades, se han desarrollado diversas formas o mecanismos que pretenden legitimar esa necesidad imperiosa de autoridad y permiten, entre otras cosas, ejercer un control directo. Ahora bien, uno de estos mecanismos disciplinarios y de control sobre el otro ha sido históricamente el cuerpo, el cual constituye el ámbito del ser más personal, íntimo y de liberación, siendo este el mayor e instantáneo medio de expresión, identidad y comunicación con aquello que es ajeno y extraño.

Ciertamente, cabría preguntarse y observar detenidamente cómo la corporalidad humana se convierte en un sistema de control y una herramienta de supeditación a otros, donde la cosificación e instrumentalización del cuerpo permite concebirlo como un lugar que ha de moldearse a consideraciones externas hasta el punto en el cual "el control de la sociedad sobre los individuos no se opera simplemente por la conciencia o por la ideología, sino que se ejerce en el cuerpo, con el cuerpo" (Foucault, 1977, p. 5)

De esta forma, se estaría hablando de una inferioridad que reúne múltiples factores y categorías de análisis al integrar el impulso 
de dominación que tiene el ser humano y su afán de soberanía y poder, aprovechando ciertas dinámicas de desigualdad y dominación. En ese sentido, y de cara a los principales referentes conceptuales abordados, se plantea que el cuerpo no se encuentra precisamente en la cúspide de una suerte de pirámide de la autonomía plena en su realización; más allá de un sentido de vulnerabilidad, se habla frente al cuerpo de una suerte de inferioridad, entendiendo que se encuentra constantemente supeditado a fines ajenos y moldeado por consideraciones externas, es decir, el cuerpo no supone un desarrollo plenamente autónomo, por el contrario, concibe una relación de desventaja frente a las formas de cosificación y control del mismo.

Ahora bien, una de las autoras que va a ejemplificar lo anteriormente expuesto es Simone de Beauvoir, quien en El Segundo Sexo -una de sus principales obras- muestra con claridad que, por ejemplo, el cuerpo de las mujeres ha sido un lugar de opresión desde el albor de los tiempos al preguntarse por el momento de inicio de la subordinación de estas (Pardina, 2015, p. 61). En ese orden de ideas, de Beauvoir plantea:

$\mathrm{Y}$ es que, dado que el cuerpo es el instrumento que tenemos para relacionarnos con el mundo, el mundo se presenta muy diferente en función de que lo vivamos de una manera o de otra. (Beauvoir, 2016, p. 69)

Sin embargo, como se propone analizar, la supeditación y opresión trasciende el plano del feminismo abordado por Beauvoir y se desplaza y refleja en las discusiones de la feminidad, masculinidad y las diferentes concepciones del género desde una perspectiva amplia.

Los sistemas han creado unas relaciones de poder, de producción, emocionales y simbólicas que se han ido transformando y definiendo justamente en los patrones de comportamiento que deben tener ambos sexos (Guevara, 2008). Sin embargo, estos patrones han ido cambiando a medida que se evolucionan y se transforman los contextos sociales; por definición, diversos y complejos. Buena 
parte de los constructos de género dependen de las particularidades históricas y culturales; sin embargo, el aterrizaje de dichos escenarios y sus condiciones trasciende el alcance de la presente ponencia. Conviene, así, aclarar que para efectos de analizar la noción de deseo en relación con las ficciones de género -y sin pretensión de convertir el lente occidental en imperativo categórico-, serán planteadas las visiones de autores europeos en diálogo con la perspectiva norteamericana de Butler.

Cierta es la trascendencia de las teorías de occidente en los estudios de género, cuyos postulados han recogido -bien para enfatizar y profundizar o desde un lente crítico y opositor- autores del espectro mundial, desde Oriente Medio hasta la riqueza del pensamiento latino del sur multicolor. La necesidad de ampliar los análisis se esboza brevemente en la propuesta de la interseccionalidad como un elemento obligante en los procesos de emancipación del cuerpo.

Ahora bien, existen diferentes maneras de expresar o ejemplificar las formas en las que el cuerpo ha sido entendido como un territorio de control, aún más cuando es evidente que el mismo es comprendido como un lugar para colonizar y modificar, situaciones que conllevan a elementos externos a plantear que son poseedores de lo ajeno y que dicha corporalidad puede ser moldeada bajo unos estereotipos, por ende, se comprende como un centro de manipulación y explotación. Al igual que los españoles se sintieron con la autorización de modificar, moldear y formar a su semejanza a América, así mismo se percibe la sociedad como dueña de todos los cuerpos, imponiendo y generando precedentes que obligan al individuo. Sin embargo, la pertinencia temática exige centrarse en el deseo, entendido desde el punto de vista de la búsqueda de una satisfacción o placer, pero que -debido a ciertas dinámicas de represión- evitan que el ser humano logre complacer sus deseos, aún más cuando se ha construido a través del "orden", la cultura tradicional e incluso las leyes una imposición de lo que es correcto, limitando las posibilida- 
des de buscar alternativas distintas para su identificación personal, sexual, cultural, etc.

En concordancia con lo anterior, la imposición sexual de un ser configura las modalidades de identificación del deseo desde la masculinidad y la feminidad, generando así una indicación acerca de lo que es posible en torno al deseo. ¿Acaso el cuerpo se ha convertido, por excelencia, en el territorio de disputa y control para demostrar y revelar la presencia e influencia del deseo como mecanismo del sistema?

En ese orden de ideas, en este escrito se pretende analizar el rol del deseo como instrumento de control sobre el cuerpo en el marco de la construcción de la feminidad y masculinidad, a la luz de los postulados de autores del siglo Xx y xxI; a su vez, examinar las nociones de 'deseo' y 'control' con base en las categorías analíticas propuestas por Sigmund Freud, Michel Foucault, Judith Butler, Paul Preciado, Elsa Ruiseñor y Raewyn Connell, que permiten identificar los sistemas y dispositivos de control que plantean los autores, para, finalmente, establecer la relación entre el deseo y el cuerpo como determinante en la construcción de las ficciones políticas de feminidad y masculinidad. Así, resulta oportuno y necesario el presente análisis, con el fin de evidenciar -desde la feminidad y la masculinidad- la construcción artificial del sujeto a partir del control sobre su cuerpo y los intentos de buscar la satisfacción del deseo.

\section{Sigmund Freud ${ }^{1}$, el deseo a la luz del psicoanálisis.}

Sigmund Freud, desde el campo del psicoanálisis, teoriza la relación directa entre la represión de los deseos a partir de la opinión popular y la institución de la medicina que corrobora y refuerza

1 Sigmund Freud nació en Freiberg, Moravia, provincia del Imperio Austríaco, en la calle Schlossergasse; fue fundador del psicoanálisis, neurólogo judío y una de las figuras más relevantes del siglo xx. Desarrolló estudios de los estupefacientes, la utilización de la hipnosis y la catarsis; por otro lado, una de sus obras más importantes es La interpretación de los sueños, publicada en 1899. 
la represión. Así, la sociedad misma es la que construye, tanto en el hombre como en la mujer, aquel ideal que debería desarrollarse, haciendo uso de ciertos valores sociales y culturales. Para ello, el psicoanálisis ha edificado una serie de dinámicas constituidas en su mayoría en un plano experiencial, generando de esta forma ciertas modificaciones a cerca de aquello que es correcto desear, situaciones que serán concebidas incluso como la inferioridad del yo.

La medicina, principalmente la relacionada con la salud mental, ha generado diversos procesos que originan una modificación parcial o completa y que buscan meramente la regulación y la modificación de los instintos primitivos del hombre y los deseos, acciones que son consecuentes a las reacciones de aquellos sometidos bajo procesos psicoanalíticos. En los procesos de investigación de Sigmund Freud se evidencia en la mayoría de los casos que el ser sometido al psicoanálisis siempre responderá con rebeldía y descontento (Freud, El yo y el ello y otras obras, 1992a).

De conformidad, aunque el 'yo' evoluciona para regular sus instintos y deseos convirtiéndose en el 'superyó', gracias a la obediencia y coerción provocada por los procesos médicos, siempre se presentará inconscientemente y a través de los sueños la necesidad de materializar los deseos más reprimidos que buscan transformar las dinámicas del presente para corregir aquello que ya fue condicionado o modificado (Freud, Fragmento de análisis de un caso de histeria, 1992b).

La evolución y el conocimiento del hombre frente a los deseos, el objeto sexual, el desear y la meta inician en la edad de la pubertad. Aunque, en primer lugar se relacionan el hombre y la mujer a partir de la pulsión sexual construida por la teoría de la fábula poética que afirma la partición del ser en dos mitades, representadas en el hombre y la mujer, desarrollándose así la necesidad de buscar su otra mitad; es por ello que al ser estas ideas constituidas por lo social, se ge- 
nera una sorpresa cuando este ser no busca su mitad contraria, sino un 'otro'/otra' igual a él: hombre en búsqueda de hombre, mujer en búsqueda de mujer (Freud, Tres ensayos de teoría sexual, 1992b).

En relación con lo anterior, Sigmund Freud propone la teoría de los invertidos, dividida en tres planteamientos: invertidos absolutos, invertidos antígenos e invertidos ocasionales. En primer lugar, desde el punto de vista absoluto -la representación de la homosexualidadel individuo se siente totalmente atraído por su mismo sexo y le resulta repugnante el sexo opuesto. Por otro lado, se plantea la premisa de antígenos, considerados como hermafroditas o bisexuales, por la cual se presenta el deseo por ambos sexos, como el reconocimiento del hombre al pensamiento femenino. Por último, los ocasionales, en donde el objeto sexual a desear no es permanente, teniendo en cuenta que la satisfacción sexual en el acto puede ser concebida por ambos sexos, pero en determinados momentos. Esta teoría de los invertidos es presentada comúnmente en todos los individuos en una época determinada. Puede concebirse antes e incluso después de la pubertad, pero puede llegar a ser no permanente; sin embargo, cabe mencionar que para los miembros de la salud de la época de finales del xix e inicio del xx esto era observado solamente como una patología provocada por una mala experiencia con el objeto sexual normal a causa de la decadencia del sistema nervioso (Freud, Tres ensayos de teoría sexual, 1992b).

Por otro lado, Freud plantea una forma diferente de representar el deseo a través del complejo de Edipo, desde el punto de vista del escrito denominado "Edipo el rey" de Sófocles; este análisis parte de los vínculos amorosos y sexuales que desarrollan los niños en su formación sexual. El niño siente atracción por su madre y la niña por su padre, afirmando así que ellos -los niños- “(...) fijan esa rudimentaria moción amorosa o la refuerzan de suerte tal que aún en la infancia, o a lo sumo en la pubertad, se convierte en algo equiparable a una inclinación sexual que, como esta, absorbe a la libido” (Freud, 
Fragmento de análisis de un caso de histeria ,1992b, p.51). Así, los planteamientos de Freud presentan que las primeras manifestaciones sexuales del ser humano no devienen de factores externos del desarrollo, sino que son procesos internos de los niños. Esto dio como resultado el descubrimiento de que la evolución y la vida sexual no se dan en la pubertad, sino que vienen en transformación desde la infancia. En relación con lo anterior, Freud plantea:

(...) el complejo de Edipo es el complejo nuclear de las neurosis, la pieza esencial del contenido de estas. En él culmina la sexualidad infantil, que, por sus consecuencias, influye decisivamente sobre la sexualidad del adulto. A todo ser humano que nace se le plantea la tarea de dominar el complejo de Edipo; el que no puede resolverla, cae en la neurosis. (Freud, Tres ensayos de teoría sexual, 1992, p. 206)

Sin embargo, más allá de la superación por el ser humano, esto constituye una concepción basada en la autoridad que dio a lugar el complejo de Edipo, e incluso la confrontación de relaciones de poder llevadas por el niño con su núcleo familiar -madre o padre- que le han desarrollado el cariño y el apego de deseo sexual amoroso. Así, Freud plantea que el apego de la niña a su padre se debe a dos circunstancias relacionadas con la castración que recae en la necesidad y el deseo de descubrir el pene, impulsando a la niña a la búsqueda o negación de su sexualidad y, por ende, rechaza tal condición o la esperanza de poseer a quien lo tiene (Vega, 2015).

\section{Michel Foucault ${ }^{2}$, el deseo transformado y reprimido por las dinámicas de poder.}

En concordancia, Michel Foucault establece una crítica relacionada al complejo de Edipo, planteando que es un forma de manifestar las relaciones de poder a través del deseo y que, en contraposición

2 Michel Foucault, nació en Francia, Poitier, en 1926 y murió en 1984 en París. Fue filósofo, historiador, arqueólogo del conocimiento y activista, por la cual tuvo gran influencia a nivel intelectual en el siglo xx; asociado al movimiento postestructuralista, sus obras más reconocidas son, Historia de la locura en la época clásica y La arqueología del saber entre otras. 
a lo planteado por Freud, no constituye algo inherente al ser humano, pues para Foucault el relato de Sófocles no es una primera manifestación del deseo, sino que constituye un hecho histórico, además, no es algo presentado en la mayoría de los casos en el desarrollo sexual del niño o niña, por lo cual el francés plantea que el complejo de Edipo es realmente

(...) una reconstrucción genealógica (...) como un discurso que, por una parte, agradece su nacimiento a las necesidades funcionales de un determinado orden de poder y que, por otra, reactúa en ese orden con el fin de perfeccionarlo en su funcionamiento. (Basuare, 2007, p. 46)

En ese orden de ideas, Foucault plantea que el psicoanálisis ignoraba otras dinámicas de poder y dominación, tales como la necesidad de deseo de los padres sobre el cuerpo de su hija en el caso de las niñas, por ende, el análisis planteado por Freud termina normalizando las dinámicas de dominación empleadas por estas clases de progenitores que permiten vislumbrar las relaciones de poder y las ansias de gobernar otro cuerpo. Así, el francés plantea que el análisis de Freud fue reduccionista en tanto solo aquellas familias burguesas de estatus social "alto" eran las únicas que podían ser sometidas a procesos de psicoanálisis. Más allá del análisis que desarrolla Foucault frente a los planteamientos de Freud, resulta necesario preguntar, ¿qué mecanismos de control sobre el cuerpo a través del deseo emergen en la sociedad, teniendo en cuenta su contexto social? Conviene mencionar que las construcciones de análisis sobre la libertad sexual desde el placer y el deseo están desarrolladas en los años sesenta, teniendo en cuenta la liberación sexual y las nuevas dinámicas de libertad, en virtud de las cuales se construyeron "nuevas formas de vida, relaciones, tratos amistosos en la sociedad, en el arte y en la cultura, de nuevas formas que se establecerán a partir de nuestras opciones sexuales, éticas y políticas" (Foucault, 2016, p.1). Si bien es cierto que dichas construcciones fueron realizadas sobre las dinámicas anteriormente mencionadas, el sexo y el deseo han sido normalizados a partir de discursos que generan "verdades" 
a cerca de la sexualidad, en línea con las relaciones de poder frente a las libertades sexuales como derecho.

En ese orden de ideas, el deseo para Michel Foucault es igual a falta, ya que se han generado, a través de la institucionalidad, estrategias para lograr que se encuentre reprimido. Esta situación producida además por la ley crea ciertos elementos morales en pro de la religión y diferentes instituciones de poder que hacen obligatorias las dinámicas que suprimen los deseos e incluso las formas de manifestarse a través del cuerpo. Ahora bien, la iglesia es una institución protagónica en la represión y desaparición de los deseos; siempre se ha tratado de construir una unidad de la moral y las leyes desde una concepción social que determine ciertas conductas, por ende, "el sujeto se ve envuelto y condicionado por un conjunto de leyes que lo determinan exteriormente, con lo cual las prácticas de "constitución de sî" deben limitarse al cumplimiento de la norma" (Cadahia, 2006, p. 66).

Así como se realiza la dominación a través de diferentes sucesos, también es necesario mencionar que a través del deseo y los placeres cumplidos resulta posible conocer diferentes concepciones, por ende, se da el descubrimiento del ser interno de la persona y se construye una nueva concepción de realidades y una alternativa de las libertades sexuales como derecho, teniendo en cuenta la relación circular entre el deseo, el acto y el placer: "el deseo que lleva al acto, el acto que está ligado al placer y el placer que suscita el deseo" (Foucault, 2002, p. 42).

En buena medida, los postulados de Michel Foucault, descritos hasta el momento, reconsideran al cuerpo a partir de la especificidad de sus elementos históricos y sociales, llegando a ser potencialidades que permiten que se configure como el territorio donde el poder puede operar sin mayor percepción. Sin embargo, ciertos cuestionamientos acerca de, por ejemplo, la relación del poder con el cuerpo, 
la investidura anterior o no del poder sobre el mismo y las posibilidades de respuesta que se encuentran en la corporalidad humana a aquellas relaciones del poder por las cuales se encuentra influenciado son retomados por autoras y autores, como Judith Butler, con el fin de aterrizar desde su pensar y desde el cuerpo cuestiones relacionadas con el sistema sexo-género y las construcciones ético-políticas que amplían el panorama (Bravo, 2018).

El análisis de los planteamientos de Butler y el aporte de Preciado obligan a una breve mención de la teoría queer. El movimiento social y político, que nace a finales de los años ochenta, recoge con propiedad el término inglés queer -considerado insulto para referirse a las sexualidades fuera del marco convencional- y transforma su carácter despectivo en la reafirmación del orgullo de ser disidente sexual. El acto político trasciende al amplio espectro de los estudios de género como una corriente crítica de las concepciones ontológicas que apelan a la 'esencia' y 'la naturaleza' de las identidades, roles y orientaciones. Así, para los autores adscritos a esta teoría, el género es mera ficción construida desde contextos socioculturales, rechazando la taxonomía de los cuerpos y todo intento de definir unas únicas formas de ser, desear y pensarse desde lo sexual.

\section{Judith Butler ${ }^{3:}$ el deseo como reconocimiento y la hegemonía de la heterónoma.}

Ahora bien, la premisa de partida, e indispensable para comprender los postulados de Judith Butler en relación con el objetivo planteado, es la noción del deseo como reconocimiento en el mar-

3 Judith Butler es una activista y filósofa estadounidense de origen judío, nacida el 24 de febrero de 1956. Sus aportes más destacados se encuentran en los campos de la teoría feminista, queer y estudios de género. Su teoría acerca de la performatividad del género y la sexualidad determina ciertos parámetros de la crítica a la condicionalidad heterosexual del feminismo. Sus obras más representativas son: Sujetos de deseo: Reflexiones Hegelianas en la Francia del siglo XX (1987), El género en disputa: El feminismo y la subversión de la identidad (1990) y Deshacer el género (2006), entre otros. 
co de lo imperioso que resulta para el ser representar una categoría relevante en la concepción de agentes externos. En conexión con la tradición hegeliana, la cual determina que el deseo se configura siempre como un anhelo de reconocimiento y que un ser social viable se determina a partir de la experiencia, Butler delimita que, si se busca obtener reconocimiento, el género -en la medida en que está animado por el deseo- buscará también ser reconocido (Butler, 2006). De esta forma, el acto de reconocer será un determinante en la construcción de ciertos vínculos y relaciones comunitarias que componen las percepciones del ser y sus acciones.

Sin embargo, las dinámicas y elementos descritos devienen en la aparición de una categorización de aquellos individuos que no resultan merecedores de dicho reconocimiento al no ajustarse o ser compatibles con la norma social que se convierte en una sede del poder diferencial de lo que es humano y lo que no. Por consiguiente,

(...) en la medida en que el deseo está implicado en las normas sociales, se encuentra ligado con la cuestión del poder y con el problema de quién reúne los requisitos de lo que se reconoce como humano y quién no. (...) ¿Se expandirá lo «humano» para incluirme a mí en su ámbito? Si deseo de una cierta manera, ¿seré capaz de vivir? (Butler, 2006, p. 15)

A partir de la noción del deseo como reconocimiento, Judith Butler cuestiona aquellos proyectos de visibilización íntimamente relacionados con las normas sociales y el poder constituido por parámetros normativos que condicionan la dependencia del "yo" irreconocible a partir de unas instituciones de apoyo social que, al no reconocer al individuo, impiden el ejercicio de su autodeterminación y establecen qué clase de cuerpo y género debe mantener.

Ahora bien, se señala la categoría 'poder' como un elemento crucial de cara al desarrollo del ser y, por ende, de ese reconocimiento que este busca y requiere para el desarrollo pleno de sus deseos. Sin embargo, cabría preguntarse si el poder resulta un elemento tan 
relevante, pero sobre todo influyente en la constitución del ser, ¿qué debería entenderse como aquello que lo integra en sí mismo? El poder se constituye por normas de categorización del ser en función del reconocimiento del que sea acreedor, aquella heteronormatividad que Judith Butler señalaría como obstáculo para la consecución de los deseos y, por ende, herramienta o forma de represión sobre el mismo ser y su cuerpo. Es por esto por lo que Butler concibe al género como una categoría construida y previamente determinada en el marco de una serie de normas sociales que constituyen la existencia del ser y, a su vez, conllevan a que sus deseos no se originen en la individualidad. Butler lo define mencionando:

Aunque ser de un cierto género no implica que se desee de una cierta manera, existe no obstante un deseo que es constitutivo del género mismo $y$, como consecuencia, no se puede separar de una manera rápida o fácil la vida del género de la vida del deseo. (Butler, 2006, p. 14)

Así, el género -y, por ende, el deseo- no es natural, sino que se determina a partir de una construcción social. Según Butler aquello que se define como hombre o mujer no se encuentra condicionado desde el nacimiento, por ende, se ha aprendido a serlo en un contexto cultural y educativo con una norma heterosexual restrictiva y con prácticas de exclusión (Filosofía\&Co, 2018). Aunque, cuestionar la "naturalidad del sexo" para Butler no significa negar la materialidad o existencia del cuerpo, sino dejar ver que, si se lo trata como una cosa verificable, se pierden de vista sus relaciones y que el acceso directo a la materialidad del cuerpo no se da sino a través del discurso (UNTREF, 2019).

Por lo tanto, para Butler la existencia de papeles biológicamente inscritos en la naturaleza del ser se determina en virtud de un discurso hegemónico que impone una unidad artificial y sustenta que la relación sexo-género-deseo se configure como el propio mecanismo o dispositivo de control sobre el individuo y, por ende, sobre el cuerpo. En ese sentido y en la misma vía de Michel Foucault, 
dichos discursos van a construir y legitimar la base discursiva de la heteronorma a partir de la irrupción de un sistema que condiciona que el sexo biológico debe ser igual a la construcción del género del individuo y que el mismo debe desear de una forma determinada; por ejemplo, quien sea mujer debe desear al hombre y construir la feminización de su cuerpo.

Ciertamente, ese discurso heteronormativo va a sustentar los postulados de Butler pues, para ella, aquello que se desea es lo prohibido, y el sujeto se va a constituir como eso que ha deseado y no se le ha permitido desear, siendo determinado por el binomio entre deseo y represión ejercido por el poder o bien, entre el deseo y la ley que le permite permanecer al prohibirlo (Padilla, 2016). Lo anterior se relaciona con la prohibición de los sujetos y las formas de deseo -propuesta por Foucault-, las cuales al ser estigmatizadas resultan más deseadas, así, la marca de 'prohibido' es una invitación a seguir deseando, creando un nuevo deseo que forma el propio sistema de poder en virtud de su fabricación y prohibición. De esta forma, las normas que devienen del discurso heteronormativo referenciado van a obrar desde lo performativo construyendo la materialidad de los cuerpos y su sexo, consolidando una hegemonía de la heteronorma obligatoria (Saxe, 2015). Ciertamente, por medio de la performatividad -entendida como las prácticas repetidas y reguladas de la vida cotidiana o los actos normalizados- se va a construir el género.

En relación, Butler desarrolla su propuesta teórica a partir de la consideración performativa del género y la identidad, de esta forma se consolida la impresión de ser de un género u otro como algo verdadero, aunque en realidad se trate del fenómeno resultante de una serie de normas establecidas -anteriormente referenciadas- y controladas por el poder (UNTREF, 2019). Al respecto, Butler plantea que "La unidad del género es el efecto de una práctica reguladora que intenta uniformizar la identidad de género mediante una heterosexualidad obligatoria”(Citada en UNTREF, párr. 6). 
Ahora bien, esa categoría del género propuesta por Butler va a tener la cualidad de ser deconstruible, es decir, de la misma forma en que se construye, puede expandirse y desmantelarse en virtud de la propia percepción del sujeto. María de los Ángeles Padilla, citando a Butler, interrelaciona lo anteriormente planteado con esta cualidad del género al expresar:

Para Butler, la vida es un dominio de pura posibilidad, en el que las restricciones y prohibiciones provienen de un esquema hegemónico (...) de tal forma que el cuerpo es solamente una estructura imaginaria que surge como consecuencia del deseo, cuya estrategia es tal, en el sujeto deseante, que éste no tiene reparo en realizar una especie de transfiguración de su cuerpo, modificándolo para adaptarse al deseo del cuerpo deseado. (Padilla, 2016, p. 715)

Entonces, el control ejercido por esa heteronorma obligatoria y las practicas que la regulan van a constituir lo correcto en una mujer y en un hombre en términos estéticos, y a configurar el control sobre la corporalidad en virtud del sistema sexo-género-deseo, más allá de una represión en sentido estricto, a partir de la construcción y desarrollo de prácticas heteronormativas limitadoras del cuerpo y del deseo que, por medio de la edificación de ciertos discursos, legitiman o imponen, por ejemplo, una forma particular de desear en función de factores biológicos. En relación con esto, "Judith Butler prefiere la concepción de Monique Wittig quien afirma que el cuerpo no es más que un producto del esquema heterosexual que lo conforma (Wittig, 2006, p. 70), así como que el género y el sexo son efectos del discurso hegemónico que busca imponer una unidad artificial” (Padilla, 2016)

Finalmente, el deseo como reconocimiento - para Butler- se encuentra limitado por una serie de prácticas reguladoras de poder, que devienen de un discurso heteronormativo y que constituyen las reglas que debe seguir la construcción del género del ser y la forma por medio de la cual este último debe desear en conformidad con, por ejemplo, su sexo biológico y, en general, el sistema heteronor- 
mativo desarrollado hasta ahora, así como sus diferentes manifestaciones en la construcción de las ficciones políticas de feminidad y masculinidad; todo ello relacionado con la edificación y limitación del cuerpo. Así, Judith Butler va a concebir al sujeto de deseo como una consecuencia de dicha prohibición impuesta culturalmente, convirtiendo al cuerpo en una suerte de receptáculo de los deseos anhelados, los cuales por la prohibición de la norma no pueden ser consumados para constituir la propia identidad del género (Padilla, 2016).

\section{Paul Beatriz Preciado4. El sistema farmacopornográfico.}

Los dispositivos foucaultianos que superan el poder soberano y proponen el régimen disciplinario desde la biopolítica y las prácticas performativas en Butler son desafiados por una episteme alternativa que invita a analizar las nuevas tecnologías como condicionantes en el sistema sexo-género. Previo al análisis del grueso teórico, es imperativo señalar su noción de 'deseo' y 'género'.

Preciado desnaturaliza al deseo en tanto lo concibe como un producto en sí mismo que se transforma en instrumento para construir y normalizar ideas particulares de la sexualización del cuerpo. Es este uno de los manifiestos de la contra sexualidad:

(...) El deseo, la excitación sexual y el orgasmo no son sino los productos retrospectivos de cierta tecnología sexual que identifica los órganos reproductivos como órganos sexuales, en detrimento de una sexualización de la totalidad del cuerpo. (Preciado, 2011, pp. 14-15)

4 Paul Beatriz Preciado es un filósofo español transgénero, nacido en 1970 en la Ciudad de Burgos. Dedica sus estudios e investigaciones a la teoría de género, sustancialmente a la crítica al binarismo que limita la subjetivación de los cuerpos a las categorías de 'hombre' y mujer'. Sus obras más representativas son: Manifiesto contrasexual (2002), Pornotopía. Arquitectura y sexualidad en «Playboy» durante la guerra fría (2010), su último libro Un apartamento en Urano. Crónicas del cruce (2019). Y el libro que será objeto de revisión en la presente ponencia: Testo yonqui (2008). 
Al género le concibe como una ficción política, un armazón sostenido por las vigas de sistemas de poder político y económico, pero amplía ese proceso de construcción y lo aterriza a la corporalidad, afirmando que:

(...) El género no es simplemente performativo (es decir, un efecto de las prácticas culturales linguístico-discursivas) como habría querido Judith Butler. El género es ante todo prostético, es decir, no se da sino en la materialidad de los cuerpos. Es puramente construido y al mismo tiempo enteramente orgánico. (Preciado, 2008, p. 81)

$\mathrm{Y}$ en ese entramado figuran la masculinidad y la feminidad como “(...) inventos de la Segunda Guerra Mundial que conocerán su plena expansión comercial durante la Guerra Fría como la comida enlatada [y] el ordenador” (Preciado, 2008, p. 81).

A diferencia de Foucault, las dinámicas de poder no emanan desde el cuerpo institucional y sus estructuras sociales, sino de otra lista de dispositivos biotecnológicos y símbolos fabricados por dos máquinas cruciales: la industria farmacéutica y la industria pornográfica. Ambas ofrecen un abanico de instrumentos que gestionan el cuerpo desde adentro y 'ordenan' la idea de sexualidad y sus manifestaciones -en una clara relación de subordinación del hombre sobre la mujer respecto al placer- y la relación directa con la industria pornográfica.

En la narrativa de Testo Yonqui ${ }^{5}$ Preciado retoma el medioevo, la estigmatización y cacería de los saberes no oficiales, entre ellos el acervo cultural de las mujeres señaladas por el poder eclesial como 'brujas', para explicar la consolidación de la medicina como ciencia y monopolio del saber en cuya voz residen aparentes verdades incuestionables.

5 Testo Yonqui, escrito en 2008, expone su teoría del modelo farmacopornográfico y, a la par, describe su experiencia personal suministrándose dosis de testosterona en gel, una práctica contrasexual que dinamita el modelo heteronormativo de sexo-género-deseo. 
El posterior desarrollo en materia investigativa da lugar al enfoque endocrinológico evidenciando la función condicionante de las hormonas en la morfología del cuerpo y la conducta del sujeto. Es así como en el periodo de posguerra nace el que sería el dispositivo principal para el control de natalidad: la píldora anticonceptiva.

La primera píldora fue rechazada en tanto eliminaba la menstruación por un tiempo, un fenómeno que se consideraba contrario a la naturaleza y que obligó a los científicos a cambiar su composición química para devolver el ciclo menstrual regular, un rasgo distintivo de la 'mujer natural'. La reflexión de Preciado apunta a cuestionar la noción de 'lo femenino' desde 'natura'; el propio ciclo menstrual, que es rápidamente asociado como condición biológica, resulta ser en un segundo momento artificio hormonal.

El español hace una fuerte crítica al 'feminismo liberal's alegando que "El golpe maestro del régimen farmacopornográfico es haberse servido de las retóricas revolucionarias del movimiento feminista de los años sesenta para hacer pasar una nueva gestión farmacopornográfica del cuerpo por una etapa de liberación sexual” (Preciado, 2008, pp. 151-152).

El dispositivo biotecnológico que controla el cuerpo termina siendo defendido a ultranza por los movimientos feministas liberales que encuentran en la píldora la forma de escindir del sexo lo obligatorio de la reproducción y añadir a la feminidad el derecho al placer del acto sexual. Resulta evidente, entonces, que a la luz de Preciado el deseo liberador de la mujer es dirigido y fabricado siempre con el amparo de la política estatal de planificación familiar.

La píldora cumple la función de control reproductivo y especialmente de la feminización del cuerpo de la mujer no solo en la regula-

6 Preciado se refiere al feminismo liberal abolicionista como uno de los aparatos ideológicos paraestatales del régimen farmacopornográfico. (Preciado, 2008, págs. 151-152) 
ridad del ciclo menstrual, sino en una lista de efectos secundarios en la apariencia física. De acuerdo con Preciado (2008), citado en Gros (2016), alivia el acné y mejora la piel, disminuye el vello corporal, produce un aumento de volumen en los senos, etc. (pp. 256-257). Aunado a los efectos 'cosméticos', la píldora tiene efectos en el estado mental, de ánimo y comportamental de las mujeres: cambios de humor, depresión y disminución de la libido sexual (Gros, 2016).

La limitación dirigida del deseo en las mujeres que fabrica la feminidad en sus cuerpos no está enmarcada en el régimen disciplinario de Foucault que vigila, controla y produce a los sujetos a partir de instituciones físicas, sostenidas por discursos que crean relaciones de poder-saber jerarquizadas. El panóptico es sintetizado en una pastilla que el individuo mismo se asegura de consumir (Quiltro, 2018). Ya no es un tercero quien ejerce vigilancia, es el propio sujeto, que en su ingenuidad se concibe libre. La mujer es presa y gendarme a la vez.

Preciado concluye: "La cuestión es administrarme la dosis farmacopornográfica necesaria de estrógenos y progesterona para transformarme en una hembra sumisa, de grandes senos, humor depresivo pero estable, sexualidad pasiva o frigidez" (Preciado, 2008, p. 14l).

Ahora bien, ¿qué lugar tiene el cuerpo del hombre? El cambio paradigmático deviene de la invención del viagra, cuyo objetivo es devolver la función eréctil y mantener en el tiempo al macho viril deseoso que descarga su libido en la mujer creada por hormonas y símbolos visuales claros; prototipos construidos que vende la industria pornográfica, fielmente consumidos por hombres que deben conservar el estado de excitación como rasgo distintivo. La dinámica es "Controlar la sexualidad de los cuerpos codificados como mujeres y hacer que se corran los cuerpos codificados como hombres" (Preciado, 2008, p. 45). 
Conviene preguntar, ¿̇cómo se manifiesta en lo simbólico? ¿Necesita el farmacopoder de redes de comunicación7 que soporten el discurso regulador del género? Preciado asiente con determinación. Aparece en escena la industria pornográfica, cuyo objetivo es la producción audiovisual de los objetos, sujetos y formas del deseo sexual y del deseo en sentido propio, para estimular al margen de la voluntad misma del individuo su imaginación de la mano con la libido.

La industria pornográfica se vale de la representación de la sexualidad en sus formas y modos desde lo masculino y lo femenino y las características de los sujetos que presionan el interruptor del placer. Presenta cuerpos estereotipados cuya posesión resulta inalcanzable, dando lugar a la crucial sensación de insatisfacción, no en un sentido negativo de inconformismo pleno, sino de 'querer más's.

Así, ambas industrias se juegan sus cartas en el marco del capitalismo, y en el medio permanece el cuerpo; en ese territorio per se de objetivación del sujeto, de disputas por el poder y en clave foucaultiana de las resistencias y disidencias desde la praxis revolucionaria al sistema sexo-género.

Después de la experiencia voluntaria de someter su cuerpo al farmacopoder de la testosterona, Preciado concluye:

Mi cuerpo podría ser un centro de reclusión a vida, un tentáculo consciente del sistema de control instalado en mi estructura biológica, un tentáculo del farmacopoder que ahora lleva mi propio nombre. Mi cuerpo, mis células son el aparato político por excelencia, un espacio público-privado de vigilancia y activación que tiene

7 Se refiere a las relaciones de comunicación en Foucault que "(...) transmiten una información por medio de un lenguaje, sistema de signos o cualquier otro medio simbólico" (Foucault, 1998, p. 9)

8 Característica que comparte con el farmacopoder. Preciado señala que ambos: "(...) reposan sobre una base somatopolítica común: El carácter toxicológico del placer; el placer es satisfacción frustrante". (Preciado, 2008, p. 211-212 
la ventaja, respecto a otras instituciones clásicas como el colegio o el ejército, de contribuir a mantener la ficción de que mi subjetividad y su soporte bioquímico, estas células, este metro ochenta aparentemente impenetrable, son mis únicas y últimas pertenencias individuales. (Preciado, 2008, p. 105)

Las lecturas de Preciado son una constante y sugestiva invitación a ampliar la consigna política de los movimientos feministas de 'lo personal es político', en el sentido del 'yo' como ficción moderna del individuo. En palabras de Preciado, todo es político. Lo personal es político, lo molecular es político, lo planetario es político. Y en el medio de este entramado está cada sujeto intentando explorar nuevas formas de subjetivación que resistan a la norma. Convertir el cuerpo en territorio de disidencia sexual y en tierra de ensayos para fabricar la libertad (Betevé, 2019).

\section{Teorías de la masculinidad}

Para hablar sobre la teoría de masculinidad se hace énfasis en los análisis realizados por la autora Elsa Guevara Ruiseñor, en su texto La masculinidad desde una perspectiva sociológica, una dimensión del orden de género; el cual contiene las interpretaciones realizadas por la autora sobre la teoría planteada por Raewyn Connell, socióloga que plantea la masculinidad hegemónica a partir del género y educación. Los hombres tienen que lidiar con preocupaciones que no siempre son reconocidas por la sociedad, temas como la paternidad, su vida emocional, las relaciones afectivas, la participación en la esfera doméstica y significados de su vida sexual, son situaciones que los llevan a seguir patrones de comportamiento que les permitirán "ejercer" sus tareas masculinas en la sociedad. Es así como en las conferencias internacionales de hombres jóvenes, los participantes se comprometen a acabar con el machismo, pero de forma problemática se ha "desgastado la legitimidad de un modelo de varón impo- 
sitivo y violento" (Ruiseñor, 2008, p.74), y este desgaste ha llevado a que se interprete el machismo como ejercicio del poder cuando en realidad es una manifestación del hombre y presupone que es una característica individual de la cual pueden desprenderse.

Dentro del análisis sociológico se plantea a la masculinidad como una dimensión del orden de género, $\mathrm{y}$, por tanto, las relaciones de poder ocupan un lugar central en la explicación de la sociedad, de las identidades y de las formas de relación de los hombres con otros hombres y con las mujeres, a su vez de mujeres entre mujeres. Kaufman (1995) afirma que los hombres deben pagar costos altos para poder detentar un poder que les genera también dolor y sufrimiento. Pero ¿cuáles son esos costos?, y ¿quién los pone? Connell traza una estructura de género que cuenta con cuatro dimensiones en las que se incrusta la masculinidad y funcionan los sistemas de control. En primer lugar, están las relaciones de poder con las que se explican las dinámicas de control de los hombres sobre las mujeres y sobre otros hombres o de las mujeres sobre otras mujeres; conexiones que llevan a determinar también las dinámicas usadas por el Estado, las corporaciones y las leyes. En segundo lugar, están las relaciones de producción, las cuales explican cómo el orden de género se ve determinado también por la división del trabajo; el sistema social asigna actividades determinadas para hombres y mujeres que conllevan a construir un orden jerárquico que diferencia lo masculino de lo femenino, además, las diferencias entre la esfera pública y la esfera privada hacen que se separen consigo la productividad de la reproductividad y pone a las mujeres en una esfera invisible. Por otra parte, las relaciones emocionales son la dimensión central de este orden de género,

La carga emocional atribuida a lo masculino y a lo femenino se dirige no sólo hacia las personas sino también hacia las instituciones y las entidades públicas. El terreno de la sexualidad está marcado por la doble moral y por la exclusión de las mujeres incluso de la apropiación de su propio cuerpo y del derecho al placer, mientras que concede a los varones dividendos en térmi- 
nos de honor y prestigio para el ejercicio de la actividad sexual. (Ruiseñor, 2008, pp. 78-79)

Finalmente, las relaciones simbólicas explican las concepciones de lo masculino y lo femenino de la sociedad. A pesar de que cada cultura ha desarrollado sus propios esquemas de interpretación, la mayoría apuntan a una autoridad masculina y a la mujer como fuente de vida. Estas interpretaciones son las que permiten entender también aspectos culturales y de comportamiento que determinan al hombre y la mujer en las diferentes esferas sociales, económicas y culturales. El entender estas dimensiones permite llegar a pensar cuales son los retos de los sexos en la sociedad y cómo estas dimensiones han tenido que transformarse debido a un "colapso histórico" sufrido por la legitimidad del poder patriarcal, la emancipación femenina y con ella las nuevas concepciones del género.

La masculinidad hegemónica es un objeto del deseo, el cual plantea un modelo de ideal de la misma el cual no corresponde necesariamente a la mayoría de los hombres y que está alejado de compararse con el "rol sexual masculino". Connell plantea la hegemonía no como un dominio absoluto, sino como un estado de situación (practicas) del hombre que sustenta su poder, lo admite y lo reproduce. En este sentido se crean concepciones de la masculinidad sexual en las que el deseo y las relaciones de este deben ser meramente heterosexuales, excluyendo otras formas en las que estas se puedan dar. Es decir, este objeto muestra los modelos masculinos que logran imponerse dentro de la sociedad y que además están organizados de forma jerárquica, exponiendo así el hecho de que hay masculinidades dominantes y otras subordinadas. Las primeras son dominantes gracias a la estrategia de consenso cultural, de esta manera se trata de un proceso dinámico, relacional y no esencialista.

Cabe resaltar de igual manera el trabajo de la socióloga Sara Martín, que busca crear un concepto de lo masculino siempre con el objetivo de no estigmatizar la esencia del hombre. En su texto "La 
importancia de distinguir el patriarcado y la masculinidad" toma como idea principal combinar el feminismo con el activismo antipatriarcal abandonando posiciones esencialistas monolíticas y así generar una breve relación en donde lo masculino debe leerse como reflexión en torno a una oposición de la masculinidad patriarcal y otros modelos alternativos y no como textos sobre la naturaleza humana en general, se tiene como objetivo repensar el buen patriarcado como una construcción atractiva también para las mujeres, pero opuesta para los hombres.

Por otra parte, el libro los desafíos de la heterosexualidad obligatoria, en primer lugar, define la heterosexualidad como una construcción social y personal del género; sin embargo, la misma no ha sido así, tal como la masculinidad y la raza blanca, pues el objetivo es generar una conciencia y conveniencia de la mutabilidad histórica para que se lleve a cabo un modelo realmente igualitario para la ciudadanía; pues es así como la heterosexualidad puede ser claramente antipatriarcal desde la lucha contra toda opresión para una libre expresión y se construya una heterosexualidad desafiante creando normatividades contra toda opresión que impida el desarrollo del individuo.

\section{Conclusiones}

El deseo y el género son productos fabricados, constructos sociales y ficciones políticas. Su desnaturalización resulta imperativa para entender las lógicas de poder a partir de dispositivos de control particulares que funcionan como instrumentos de objetivación del sujeto y condicionan su identidad, obligándole a inscribirse en categorías de auto represión, binarias y heteronormativas. Es así como el deseo termina siendo producto del poder y a la vez instrumento de control sobre el cuerpo. 
Los autores del siglo xxi retomarán las reflexiones de Foucault respecto a la vigilancia y control, las tecnologías y dispositivos que constituyen la relación de poder-saber y el monopolio de las verdades institucionales, para abordar los nuevos postulados de las teorías de género que critican la omisión de los cambios paradigmáticos con respecto a los desarrollos de nuevas nociones de performance y saberes tecnológicos.

El cuerpo desde su condición material es atravesado por relaciones biopolíticas de poder cultural, institucional, técnico y simbólico que le convierten en un territorio de control constante, cuyo ejercicio es asumido por el propio sujeto que obedece, consume y se moldea conforme al paradigma heteronormativo.

La masculinidad ha sido estigmatizada por los sistemas de control que han llevado a que el hombre determine su comportamiento como privilegiado frente al deseo y el uso del cuerpo, para detenerse a analizar su sujeción a las dinámicas de control que son usadas sobre cualquier expresión del género.

Los estudios de género posmodernos invitan a la búsqueda crítica y constante de dispositivos, vías y narrativas de escape y emancipación que habiliten otras formas de ser. Atendiendo el llamado, se proponen dos escenarios que, si bien su contenido desborda el objeto de la ponencia, sirven como un ligero esbozo para puntualizar fenómenos actuales merecedores de análisis particular.

Las personas 'no binarias' rompen el marco de las visiones dualistas del género y suponen un punto de quiebre en los imaginarios sociales estereotipados en clave masculino y femenino. No resulta tarea sencilla construir una imagen mental rápida de cómo deben ellos desear, hablar o vestir, ya que es una persona que no se identifica con ninguno de los dos gé- 
neros. El vacío de preconcepciones al que reta esta disidencia es una interesante muestra de un camino alterno que pareciese no haber sucumbido aún a las lógicas limitantes del sistema sexo-género. Los cuerpos de los 'no binarios' son tierra sin colonizar.

El carácter disruptivo de las teorías queer permite evidenciar esencialismos amenazantes que devienen en móviles de exclusión, incluso desde las mismas alas progresistas. Los feminismos que unifican el 'ser mujer' no solo omiten el abanico de pluralidades de la feminidad, también marginan las condiciones 'no naturales' que acompañan al género: etnia, raza, estatus socioeconómico, etc. Así, el enfoque de la interseccionalidad se propone como eje transversal a todos los campos de transformación social y constituye una herramienta clave y urgente en los procesos de subjetivación. La deconstrucción de las conquistas sobre el cuerpo que compelen a desear de modos únicos obliga a incluir todas las otras ficciones sociales fuera del género que han sido fuentes de opresión. Al final, se trata de luchas reunidas en una misma consigna: Libertad para dignificar la vida.

\section{Referencias}

Allá, M. (2002). Sigmund Freud

Basuare, M. (2007). El psicoanálisis como saber-poder. Sobre el funcionalismo de Foucault y su crítica al complejo de Edipo. Signos Filosóficos, 9(18), 41-80.

Beauvoir, S. d. (2016). El Segundo Sexo. Epublibre. Obtenido de http://solidaridadobrera. org/ateneo_nacho/libros/Simone\%20de\%20Beauvoir\%20-\%20El\%20segundo\%20 sexo.pdf

Betevé (12 de abril de 2019). Entrevista a Paul B. Preciado: "Soy un disidente del sistema sexo-género" - Àrtic | betevé. [Archivo de video] Barcelona. Recuperado de https:// www.youtube.com/watch?v=Aa-RiOuYiE4 
Bravo, R. (2018). Cuerpo y poder. Una conversación entre Foucault y Butler. Dorsal. Revista de Estudios Foucaultianos, (4), 63-85. http://revistas.cenaltes.cl/index.php/dorsal/article/view/225

Butler, J. (2006). Deshacer el género. Barcelona: Paidós.

Cadahia, M. L. (2006). El rol del placer en Foucault. Revista de la Universidad Nacional de Córdoba, 59 - 73.

Filosofía\&Co. (2018, 24 de septiembre). Judith Butler: "No estoy segura de queeste siglo sea femenino". Recuperado de https://www.filco.es/judith-butler-noestoy-segura-de-que-este-siglo-sea-feme nino/

Foucault, M. (2002). Historia de la sexualidad 2: Uso de los Placeres. Buenos Aires: Siglo $\mathrm{XXI}$.

Foucault, M. (2016). Sexo, Poder y Gobierno De La Identidad (Entrevista). Traducción de Pérez Bueno L. Recuperado de http://capacitacioncontinua.sociales.uba.ar/wp-content/ uploads/sites/25/2016/ 09/FOUCAULT-Sexo-poder-y-gobierno-de-la-identidad.pdf

Foucault, M. (1977). Historia de la medicalización. Educación médica y salud, 11(1), 3-25.

Freud, S. (1992). Obras Completas Sigmund Freud. Fragmento de análisis de un caso de histeria y Tres ensayos de teoría sexual y otras obras. (Vol. Número 7). Buenos Aires: Amorrortu editores.

Freud, S. (1992). Obras Completas Sigmund Freud. El yo y el ello y otras obras. (Vol. Número 19) Buenos Aires:

Amorrortu editores.

Giraldo, L. M. (1997). El deseo: Dimensión que nos separa de los animales. CES Medicina, 11(1).

Gros, A. E. (2016). Judith Butler y Beatriz Preciado: una comparación de dos modelos teóricos de la construcción de la identidad de género en la teoría queer. Revista Civilizar Ciencias Sociales y Humanas, 16(30), 245-260. Recuperado de http://www.scielo. org.co/pdf/ccso/v16n30/v16n30a18.pdf

Guevara Ruiseñor, E. (2008). La masculinidad desde una perspectiva sociológica. Una dimensión del orden de género. Sociológica, 23(66), 71-92. Recuperado de http:// www.scielo.org.mx/pdf/soc/v23n66/v23n66a4.pdf 
Kaufman, M. (1995). Los hombres, el feminismo y las experiencias contradictorias del poder entre los hombres. Género e identidad. Ensayos sobre lo femenino y lo masculino, 123-146.

Martin Alegre, S. (2011). Desafíos a la heterosexualidad obligatoria. Barcelona: Universidad Autónoma de Barcelona.

Monge, J. (20 de mayo de 2014). El lugar del deseo en Michel Foucault. Consecutio Rerum. Recuperado de http://www.consecutio.org/2014/05/el-luguar-del-deseo-en-michelfoucault/\#_f tn9

Padilla, M. (2016). La noción de cuerpo en Judith Butler: una estructura imaginada, producto del deseo. Daimon. Revista Internacional de Filosofía, 5, 713-718. Recuperado de https://revistas.um.es/daimon/article/view/269721

Pardina, T. L. (2015). El cuerpo de las mujeres como locus de opresión/represión. Investigaciones Feministas, 6, 60-68.

Preciado, P. B. (2008). Testo Yonqui. Madrid: Espasa, Calpe, S. A.

Preciado, P. B. (2011). Manifiesto Contrasexual. Barcelona: Anagrama.

Quiltro. (13 de abril de 2018). El Farmacopoder en Beatriz Paul Preciado: El Poder que se Traga. [Archivo de video] Recuperado de https://www.youtube.com/ watch?v=Bm9KW0pq30U

Saxe, F. (2015). La noción de performatividad en el pensamiento de Judith Butler: queerness, precariedad y sus proyecciones. Estudios Avanzados, (24). https://www.redalyc.org/jatsRepo/4355/435543383002/html/index.html

UNTREF (Universidad Nacional de Tres de Febrero) (2019, 8 de abril). Una introducción al pensamiento de Judith Butler. https://www.untref.edu.ar/mundountref/introduccionteoria-judith-butler

Vega, V. (2015). El complejo de Edipo en Freud y Lacan. Recuperado de http://www. psi. uba. ar/academica/carrerasdegrado/psicologia/sitios_catedras/obl igatorias/055 adolescencia1/material/archivo/complejo_edipo. pdf. 